\title{
On the Applicability of Gassmann Model in Carbonates
}

\author{
Ravi Sharma*†, Manika Prasad*, G C Katiyar", Ganpat Surve* \\ * Indian Institute of Technology, Bombay, Powai, Mumbai - 400076 \\ Marine Geophysical Operations, Oil and Natural Gas Corporation Ltd., Mumbai - 400093 \\ ₹ Third Eye Centre, Oil and Natural Gas Corporation Ltd., Mumbai - 400051
}

\section{Summary}

\begin{abstract}
It is important to choose an acquisition technique and geometry, which produces minimum footprints. Uniform distribution of fold, offset and azimuth for all the bins will reduce the footprints to a great extent but it is not achievable in any $3 \mathrm{D}$ practical geometry. Achieving the uniform nominal fold and minimizing the variation of offset and azimuth sampling across the bins is also the prime objective of the designer in designing the 3D survey geometry so that the geometry creates minimum footprints.

The Slant geometry, which provides better offset distribution but narrow azimuth, is widely used in acquisition of 3D seismic data by Geophysical Crews of ONGC. In all the investigations carried out with Slant Geometry in acquiring 3D seismic data, the active spread for all the shots of salvo had been kept same. But the variation of Xmin, Xmax provided by the slant geometry as used in ONGC is more. It has been analyzed and found that by keeping the near offsets same for all the shot points of the salvo will provide uniform fold, equally good unique foldage, offset and azimuth but with minimum variation of Xmin, Xmax and Xavg across the bins. Hence, this suggested option of slant geometry will minimize the acquisition footprints. The analysis of the two options is compared in detail and it is shown that new options will have minimum acquisition footprint
\end{abstract}

\section{Introduction}

Petrophysical (porosity, permeability) properties, and with them seismic properties, of carbonate rocks can change significantly due to dissolution, precipitation, and cementation processes. As shown by Eberli et. al. (2003), the matrix structure undergoes drastic change, with pores taking the matrix place and vice versa. Under such conditions, a relationship between the seismic, petrophysical and rock physics attributes of a reservoir system can assist in better understanding of such complicated limestone reservoirs.

Most laboratory research on saturation effects carried out in sandstones has shown that the Gassmann's theory can predict fluid related changes in seismic velocities. Porosity is the most important factor controlling sonic velocity. But various studies show that pore type, pore fluid compressibility, and variations in shear modulus due to saturation are also important factors for velocities, especially in carbonate rocks. Only a few studies have investigated the effect of saturation on velocity in carbonate rocks. Rafavich et al. (1984), Wilkens et al. (1984) concluded that porosity is the major factor influencing velocity and that pore-fluid type has no statistically relevant influence. In contrast, Japsen et al. (2000) and Assefa et al. (2003) measured consistently lower shear modulus for water-saturated samples of low porosity chalk and oolitic grain-packstone, respectively. Their data implies that in carbonate rocks, the assumption of constant shear modulus in Gassmann's theory might not always be valid. We have investigated the effect of saturation on different set of carbonates and the applicability of the Gassmann's equation for predicting saturation and porosity effects in carbonate rocks. Assuming linear elasticity and the rocks to be isotropic and homogeneous, we calculated shear wave velocities from measured dry Vs and saturated density. Figure 2(a) shows that the variation in shear modulus is not consistent with Gassmann's assumptions of a saturation-independent shear modulus. Large amount of difference in the $\mathrm{Vp} / \mathrm{Vs}$ ratios of the dry and saturated values when plotted against $\mathrm{V}_{\mathrm{P}}$ and porosity is matched by the plot of Gassmann's $\mathrm{V}_{\mathrm{P}} / \mathrm{V}_{\mathrm{S}}$, versus $\mathrm{V}_{\mathrm{P}}$ and porosity

Mineralogical and petrophysical description of the samples: The mineralogy of the first data set (Wang, 2002) is mainly calcite with low porosities ranging from $0.6 \%$ to $16.2 \%$. Brine was used as the saturating fluid. The second data (Rogen, 2002) was measured on samples from the chalk reservoirs of Danish North Sea. Rogen (2002) gives compaction as the primary porosity-controlling factor and textural variation as a secondary porosity-controlling factor. The chalk samples are either the mudstone $(<10 \%$ large grains) or wackestones ( $>10 \%$ large grains). The mineralogy is mainly calcite with less than 5\% quartz, kaolinite, smectite and others. Porosities are high and vary from $14 \%$ to $45 \%$. The gas permeability ranges from $0.44 \mathrm{mD}$ for the clay rich chalk to $8.87 \mathrm{mD}$ in comparably clean chalks. The third high 

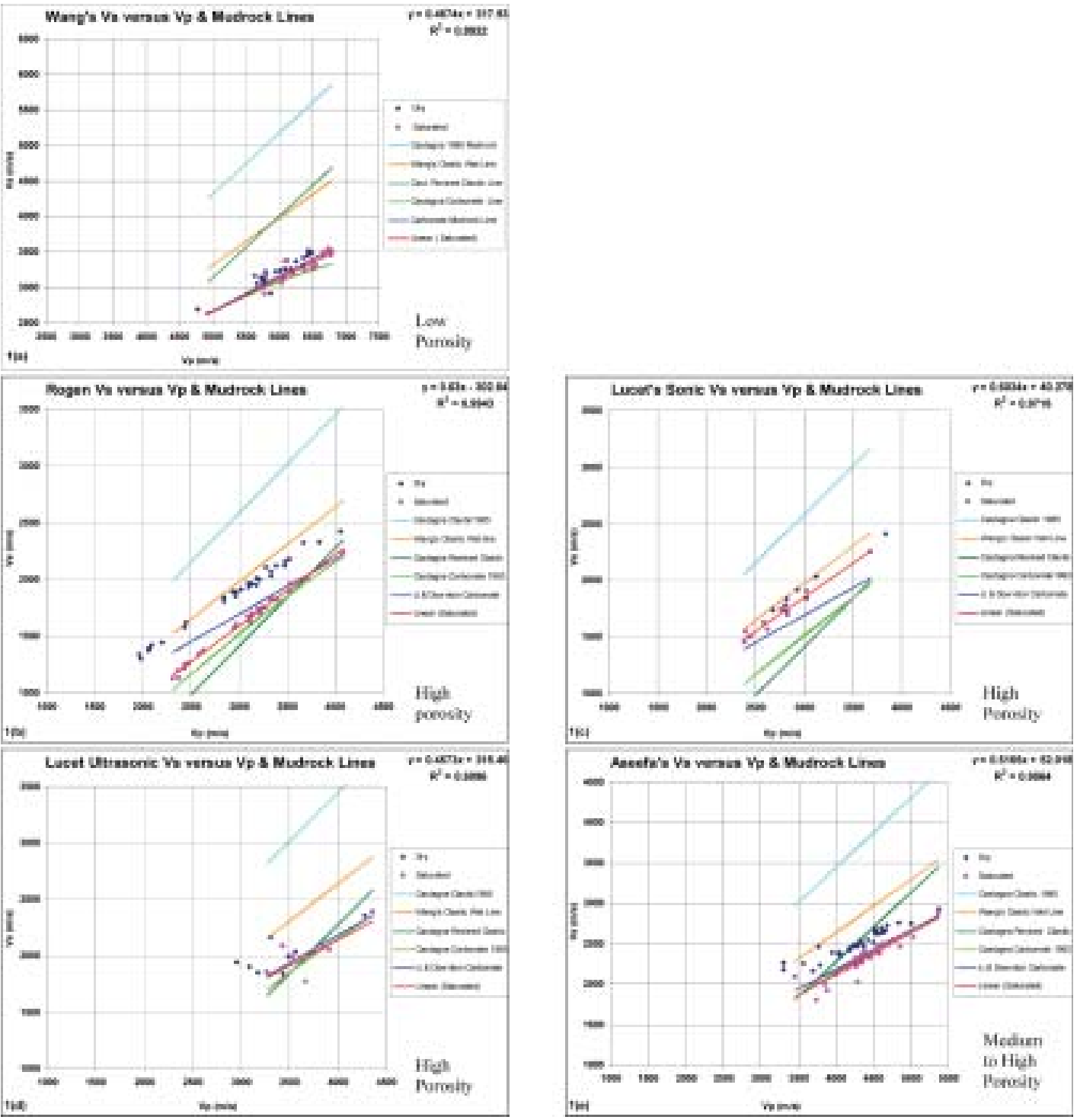

Fig.1 Trend lines for $\mathrm{V}_{\mathrm{S}}$ versus $\mathrm{V}_{\mathrm{p}}$ are plotted for, a) Wang, b) Rogen, c) Lucet's Sonic, d) Lucet's Ultrasonic and e) Aseefa's data set. All these trend lines are compared against the different Mudrock lines. In all the plots, the trend line for saturated velocities better matches the Carbonate Mudrock Line by Li \& Downton (2000), except for the Lucet's sonic.

porosity data set (Lucet, 1989) contained two sets of velocity measurements made at sonic and ultrasonic frequencies. The porosities ranged from near $20 \%$ to as high as $42 \%$. The permeabilities ranged between $7 \mathrm{mD}$ to as high as $1853 \mathrm{mD}$. The fourth set of datawith medium to high porosity (Aseefa et al., 2003) was from the Great Oolitic Limestone formation, predominantly composed of oolitic skeletal grainstones, (grain supported and lacking carbonate mud), packstones (grain supported and containing mud) to wackestones (mud supported and containing more than $10 \%$ grains). The rocks are mainly composed of calcite and dolomite with minor amounts of quartz and feldspar. The porosity varied from $3.2 \%$ to $16.7 \%$ with intergranular pores (upto 300 microns) as the primary porosity and moldic porosity with the ooid grains as the secondary porosity. The permeabilities of the samples ranged from $0.1 \mathrm{mD}$ to $7 \mathrm{mD}$. All the data have ultrasonic measurements of compressional and shear wave velocities made at $50 \mathrm{MPa}$, except Lucet (1989) data that also has measurements at sonic frequencies. Water was used as the saturating fluid except in Wang's experiments that used brine. The values of density and bulk modulus of the fluid and rock minerals used in this study are given in table 
1. Among the data used here, in Aseefa's data the mineralogy is other than calcite with dolomite and quartz proportions ranging up to $55 \%$, and gypsum and feldspar up to $15 \%$. In this case we have used the Voigt-Ruess-Hill (VRH) average (Hill, 1952) to calculate the grain bulk modulus $\left(\mathrm{K}_{\mathrm{m}}\right)$.

\section{Method for calculation}

The Gassmann's (1951) relation (eq.1) is used to calculate the saturated velocities and other related reservoir attributes.

$\mathrm{K}^{*}=\mathrm{K}_{\mathrm{d}}+\left[\left(1-\mathrm{K}_{\mathrm{d}} / \mathrm{K}_{\mathrm{m}}\right)^{2} /\left\{\phi / \mathrm{K}_{\mathrm{f}}+(1-\phi) / \mathrm{K}_{\mathrm{m}}-\mathrm{K}_{\mathrm{d}} / \mathrm{K}_{\mathrm{m}}{ }^{2}\right\}\right]$
$\mu^{*}=\mu_{\mathrm{d}}$

Where, $\mathrm{K}_{\mathrm{f}}, \mathrm{K}_{\mathrm{m}}, \mathrm{K}_{\mathrm{d}}, \mathrm{K}^{*}$ refer to the bulk modulii of, respectively, the pore fluid, the rock forming minerals (grain), the air-filled rock-frame (the dry sample), and the fluid filled rock-frame (saturated sample). $\phi$ represents porosity and $\mu_{\mathrm{d}}$ and $\mu^{*}$ refer to the shear modulii of, respectively, the dry sample and the fluid saturated sample. Bulk density was calculated using

$$
\rho^{*}=\phi \rho_{\mathrm{f}}+\rho_{\mathrm{d}}
$$

Where, $\rho^{*}, \rho_{\mathrm{f}}$ and $\rho_{\mathrm{d}}$ are, respectively, the densities of the fluid filled rock, the fluid filling the pores, and the dry rock. $\rho_{d}$ can also be expressed as $\rho_{d}=(1-\phi) \rho_{m}$, where, $\rho_{m}$ is the density of the matrix (rock forming minerals). To calculate the velocity and the bulk modulus of the dry rock, and the deviation of saturated from dry and that of Gassmann's from saturated, we have used the following equations.

$\mathrm{K}_{\mathrm{d}}=\rho_{\mathrm{d}}\left(\mathrm{V}_{\mathrm{P}}^{2}-4 / 3 \mathrm{~V}_{\mathrm{s}}^{2}\right)$

.........3

$\mu_{\mathrm{d}}=\rho_{\mathrm{d}} \mathrm{V}_{\mathrm{s}}^{2}$

$\mathrm{V}_{\mathrm{p}}^{2}=\mathrm{K}+4 / 3 \mu_{\mathrm{d}}$

$\ldots \ldots .4$

........5

\section{Measured saturated}

$$
\begin{aligned}
& \text { Deviation in \% } \\
& =\left[\left\{\text { Saturated }\left(\mathrm{V}_{\mathrm{p}(\text { or s })}\right)-\operatorname{Dry}\left(\mathrm{V}_{\mathrm{p}(\text { or s })}\right)\right\} / \operatorname{Dry}\left(\mathrm{V}_{\mathrm{p}(\text { or s })}\right)\right] \times 100
\end{aligned}
$$

Gassmann Deviation in \%

$=\left[\left\{\operatorname{Gassmann}\left(\mathrm{V}_{\mathrm{p}(\text { ors })}\right)-\operatorname{Saturated}\left(\mathrm{V}_{\mathrm{p}(\text { or })}\right)\right\} / \operatorname{Saturated}\left(\mathrm{V}_{\mathrm{p}(\text { (or })}\right)\right] \times 100$

\section{Results}

A comparison between the measured shear and compressional velocities for both dry and saturated samples (fig.1a, 1b, 1c, 1d, 1e), shows that for the high porosity data, there is an appreciable reduction in the saturated shear velocity values and the shift reduces with decreasing porosity (Wang, 2002). Comparisons between linear trend lines for the saturated velocity data, with the Mudrock relations from Castagna (1985; 1993), Wang and Nur (2000), and Li \& Downton (2000) show that all the saturated trend lines lie markedly below the relations for clastics. The carbonate Mudrock line of Li \& Downton (2000) has the closest match with the linear best fit for the saturated velocity data. However, the fit is not as good for the entire data range. We have examined the cause of this mismatch with the help of other attribute plots. Interestingly, in all the high porosity data, the wet line from Wang and Nur (2000) shows a good correlation with the dry velocity trends.

Analyzing the plots of bulk and shear modulii, for dry, saturated and Gassmann derived values (fig. 2a) we find that the saturated shear modulus are lower than the dry values for some data sets This observation is violates Gassmann's assumption of fluid not interacting with the matrix. For the other data sets (Wang, 2002 and Lucet, 1989), the saturated shear modulus values are only slightly higher than the dry values. The saturated bulk modulus is higher than the dry modulus for a majority of the data (Fig.2b), in agreement with the theory of acoustic wave propagation in saturated media. However, results from Gassmann's equations show a mismatch with measured values. The bulk modulus is underestimated in cases where shear modulus does not change with saturation. For the rest of the data sets, Gassmann's equations overestimate bulk modulus values (fig. 2c). Figs.2d and 2e show that the bulk and shear moduli are inverse functions of porosity. The difference between dry and saturated bulk moduli also appears to depend on porosity. For bulk modulus, it varies from $15 \mathrm{GPa}$ in the low porosity range of 1 to $10 \%$ and goes down $5 \mathrm{GPa}$ at high porosities of $45 \%$. For shear modulus, it varies from $+/-2.5$ $\mathrm{GPa}$ in the low porosity range (1-10\%) to almost negligible in the high porosity range of 40 to $45 \%$.

Figs. 3 and 4 compares the relation between dry saturated and Gassmann calculated velocities in comparison with the saturated velocities. There is a slight increase in the saturated $\mathrm{V}_{\mathrm{P}}$ (fig.3a) for almost all the data sets. However for saturated $V_{S}$ (fig. 3b), we see an appreciable lowering of velocities for all the high \& medium porosity data (in direct co-relation with fig.2e). Furthermore for Wang (2000) and Lucet ultrasonic (1989) data with very different range of porosities and permeabilities, there is no change shear velocity after saturation. The Gassmann predicted compressional velocities (fig.4a) have overestimated the measured compressional velocities. On the other hand, the Gassmann derived shear velocities overestimates the measured shear velocities for high porosity data sets (fig. 

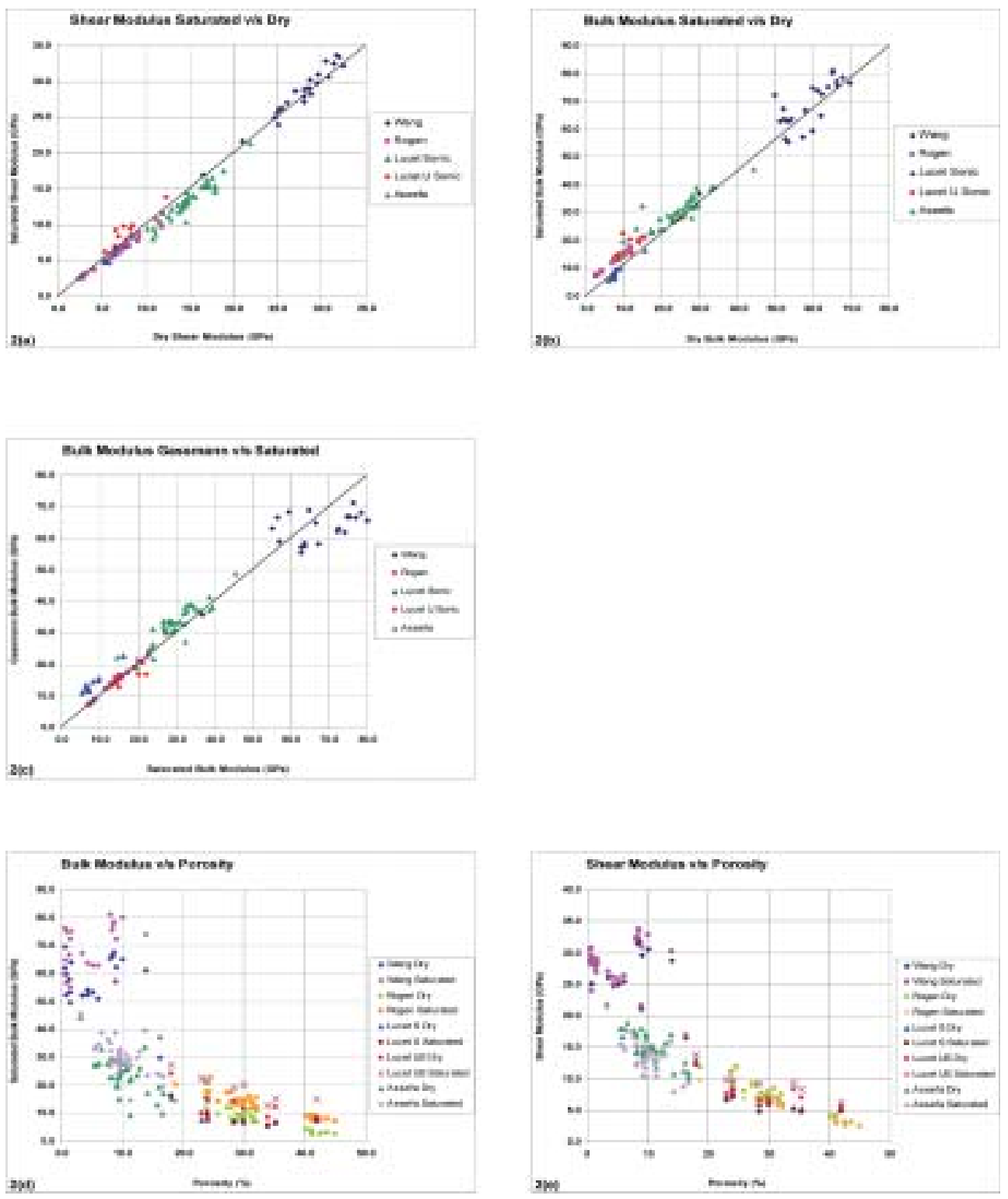

Fig.2 Plotting of rock moduli is done for, a) shear modulus saturated v/s dry, b) bulk modulus saturated v/s dry and c) bulk modulus Gassmann v/s saturated. The increase in bulk modulus is visible across all the data sets except for Lucet's sonic and a few points of Wang's data and similarly a decrease of shear modulus is visible across all the data sets except the Lucet's ultrasonic and the Wang's data. The variation between the saturated and dry values for these elastic moduli is observed to be inversely proportional to the porosity As shown in d) bulk modulus vs. porosity and e) shear modulus vs. porosity, the variation in difference between saturated and dry is from $15 \mathrm{GPa}$ to $5 \mathrm{GPa}$ in bulk modulus with increase in porosity and from +/- $2.5 \mathrm{GPa}$ to negligible for shear modulus with increase in porosity.

4b). For estimating the saturated velocities, the Gassmann's equations appear to fail in carbonate rock that shows a variation for carbonate in shear modulus due to saturation.

Eq. $6 \& 7$, representing 'Measured Saturated Deviations' and 'Gassmann Deviations' respectively, are used for calculating the deviation in velocity estimation by Gassmann from that of lab calculated. Most of the data values of saturated $\mathrm{V}_{\mathrm{P}}$ (fig.5a) show a positive deviation of up to $7 \%$ for the porosity ranges of $0-35 \%$. For higher porosities ranges, the deviations are higher and ranges from $7 \%$ to $18 \%$. The deviations in the saturated $\mathrm{V}_{\mathrm{S}}$ (fig.5b) from that of dry Vs are only 0 to $+/-3 \%$ in the porosity ranges of $0-5 \%$. For higher porosities, the deviations goes down to $-18 \%$. The line of density effect accounts for only $8 \%$ of the negative shift in velocities. For an isotropic and homogeneous rock, 

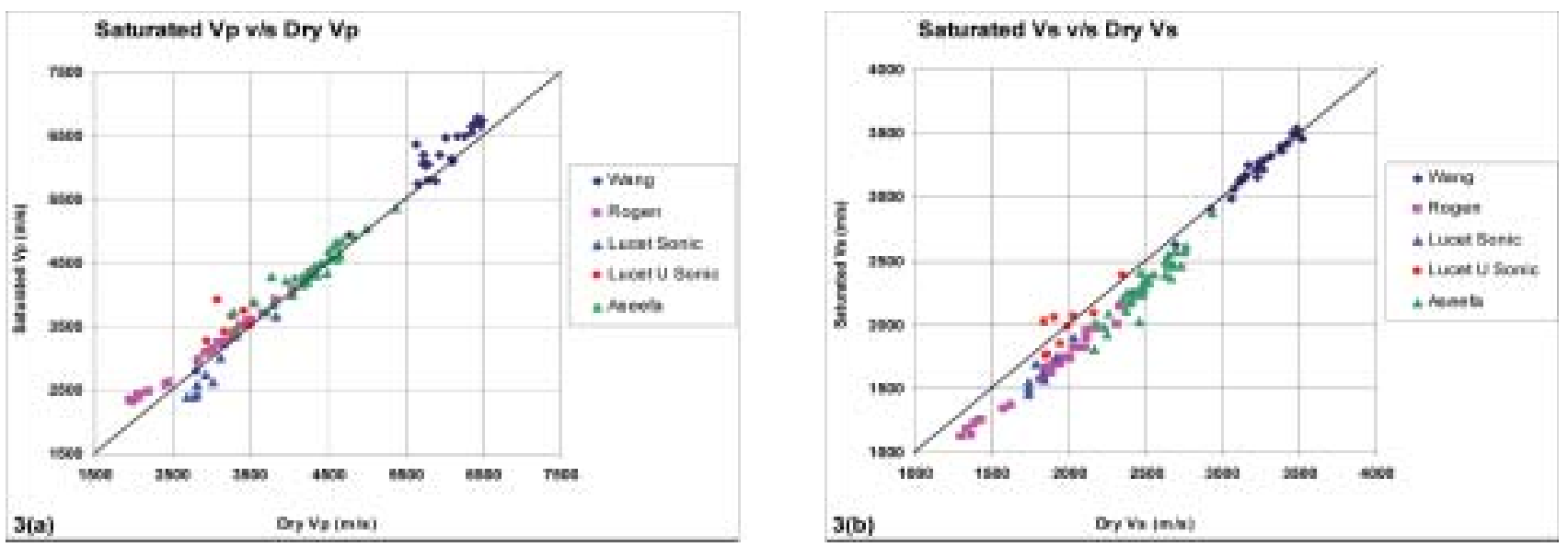

Fig.3 Variation in velocities of a saturated and dry rock for a) compressional velocities and b) shear velocities are depicted here. Saturated $V_{P}$ is overestimated for most of the data points except the Lucet's sonic and saturated Vs is underestimated for most of the data points except the Lucet's ultrasonic and Wang's data, which are on or around the line of equal values. This noticeable variation in the saturated shear velocities indicates some process other than density contribution to have played a role in the rock fluid system.
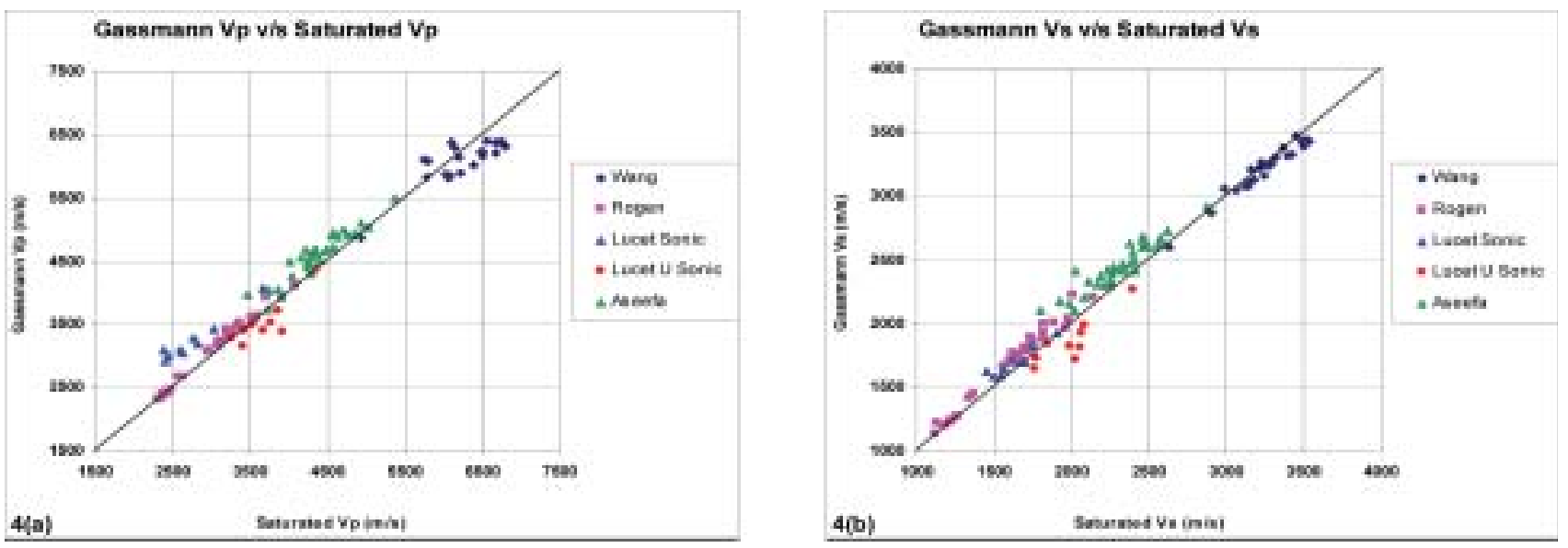

Fig.4 The Gassmann predicted values of a) compressional velocity, overestimates the saturated velocities except for the Lucet's ultrasonic and Wang's data points, and b) shear velocity are overestimated for all the data sets except for Lucet's ultrasonic and that of Wang's.

the rest of the deviation can be attributed to the weakening of shear modulus due to the saturating fluid. The Gassmann deviation in $\mathrm{V}_{\mathrm{P}}$ (fig.6a) lies between $-5 \%$ to $+5 \%$ for low porosity (up to $5 \%$ ) and varies from up to $15 \%$ to almost negligible as the porosity varies form 5 to $45 \%$. Similarly the positive deviations in $\mathrm{V}_{\mathrm{S}}$ (fig.6b), narrows down from $15 \%$ at $10 \%$ porosity to $8 \%$ at $40 \%$ porosity. For a majority of the data sets that have experienced shear weakening, the deviations are in inverse relationship with porosity. Fig.5c displays a decrease in $\mathrm{V}_{\mathrm{S}}$ up to $18 \%$ and increase in $\mathrm{V}_{\mathrm{P}}$ up to $27 \%$. Data plotting along the line of zero $\mathrm{V}_{\mathrm{S}}$ deviations, indicates that the data has remained unaffected by the presence of fluid and has only experienced density effects. Similarly in Gassmann's deviation crossplot the overestimation of $\mathrm{V}_{\mathrm{S}}$ is up to $18 \%$ and overestimation of $\mathrm{V}_{\mathrm{P}}$ up to $24 \%$. A closer look at the data indicates that the shear weakening effect is ignored and both the velocities are over predicted.

As most of the rock samples do not comply with Gassmann assumption, plots of $\mathrm{V}_{\mathrm{P}} / \mathrm{V}_{\mathrm{S}}$ against porosity and $\mathrm{V}_{\mathrm{P}}$ help us to analyze the effect of porosity and fluid content and to see that how well Gassmann can emulate these results. Fig.7a shows that $V_{P} / V_{S}$ versus porosity, for dry samples, decreases with increase in porosity down to 1.45 at a porosity of $45 \%$. The ratio for the saturated values at lower porosity lies around 1.97 (similar to dry values) and shows only minimal positive deviation of 0.05 . The high porosity data, reaches a maximum of 2.10 and shows a positive deviation of up to 0.60 . Similarly, saturated $\mathrm{V}_{\mathrm{p}} / \mathrm{V}_{\text {-S }}$ when plotted against 

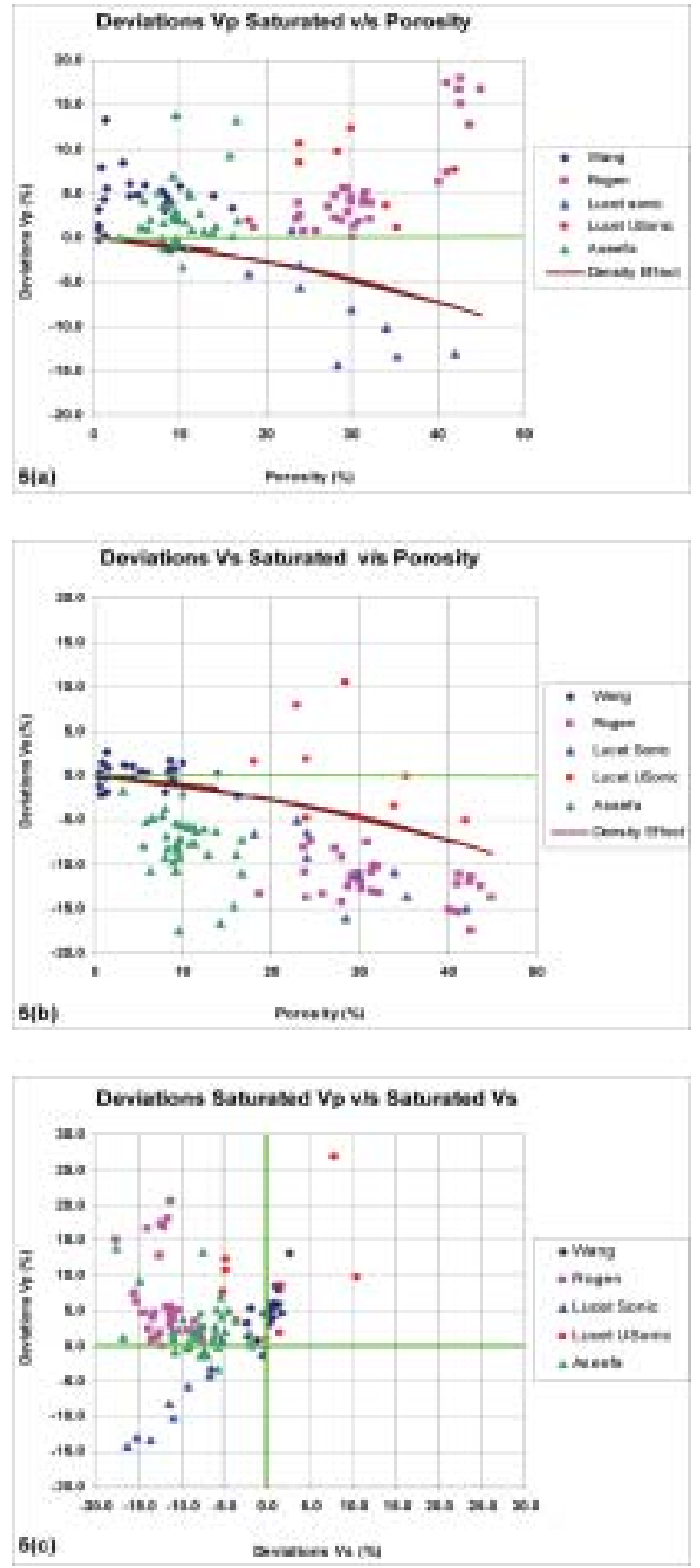

Fig.5: Deviations of Saturated velocities from that of Dry are plotted versus porosity for, a) compressional velocity and b) shear velocity. Vp suffers a deviation of $+7 \%$ for most of the data points except that of Lucet's sonic and goes up to $+18 \%$ with increase in porosity. The bulk effect of fluid is definitely more than the density effect which intends for a -ve deviation of Vp. However, Vs shows a ve deviation in velocity which linearly increases with increase in porosity, and is much more than what is accounted by the density effect. c) Deviation in Vp versus deviations in Vs, shows that except for Wang's data and Lucet's sonic, the data has observed bulk strengthening and shear weakening which increases with increase in porosity.
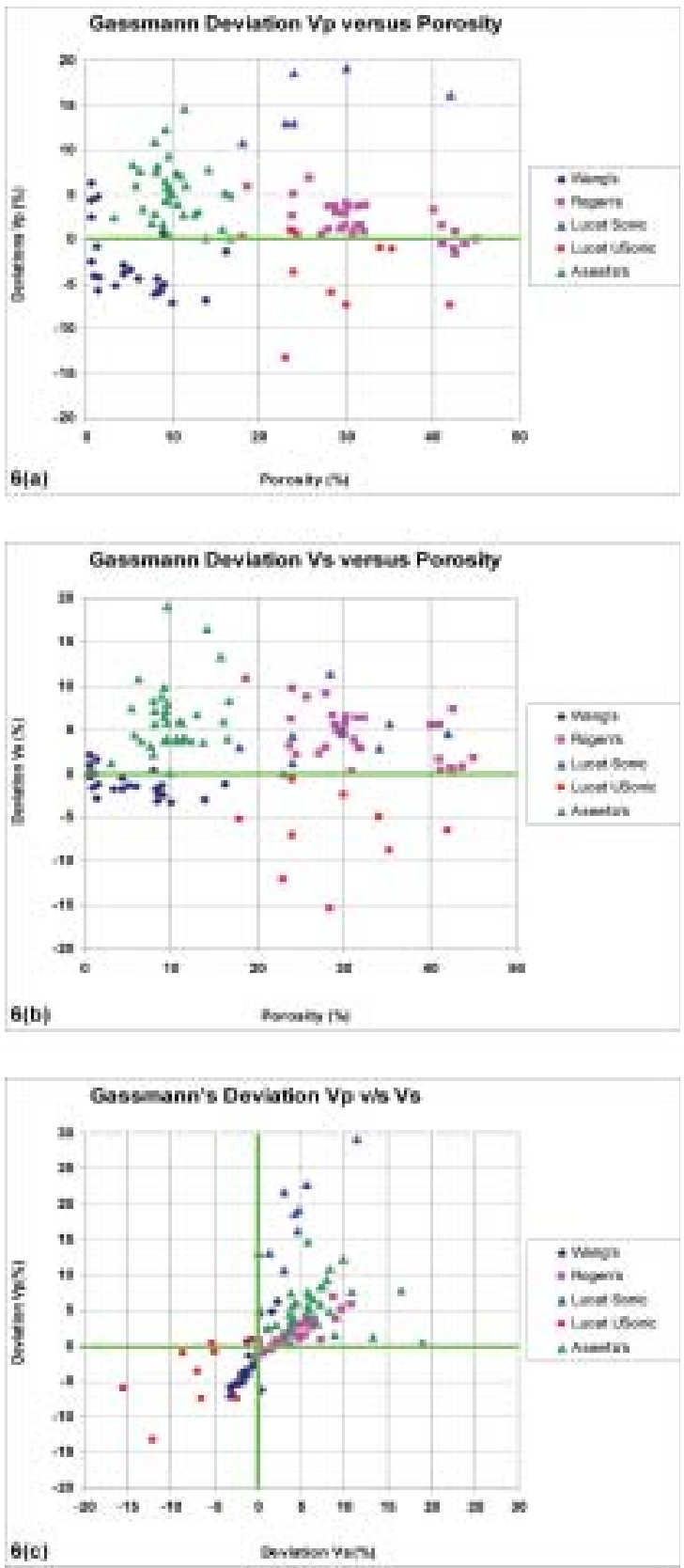

Fig.6 : Deviations of Gassmann velocities from that of Saturated are plotted versus porosity for, a) compressional velocity and b) shear velocity. Vp suffers a deviation of $+5 \%$ to $-5 \%$ for $0-5 \%$ porosity data. As the porosity increases, deviations in $\mathrm{Vp}$ varies from $+15 \%$ to almost negligible at the highest porosity of $45 \%$. However, Vs except for the low porosity shows a +ve deviation of $16 \%$ at $10 \%$ porosity in velocity which gradually reduces to $+8 \%$ at the highest porosity. c) deviation in $\mathrm{Vp}$ versus deviations in Vs, shows that except for Wang's data (almost no deviation) and Lucet's ultrasonic, the data has been over estimated. 

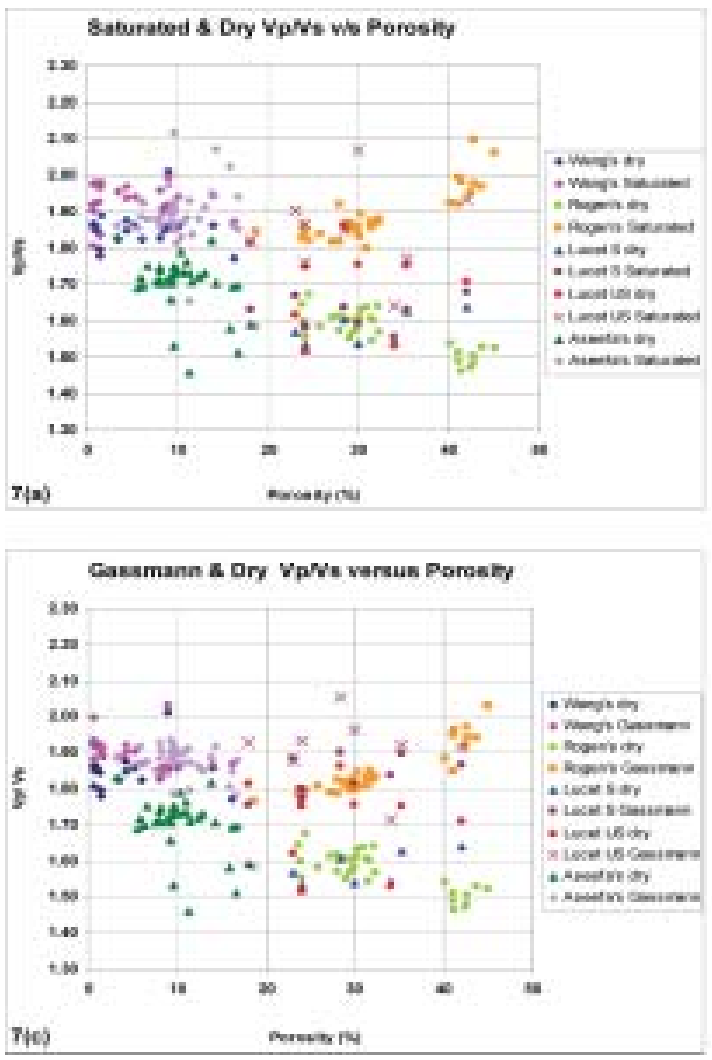
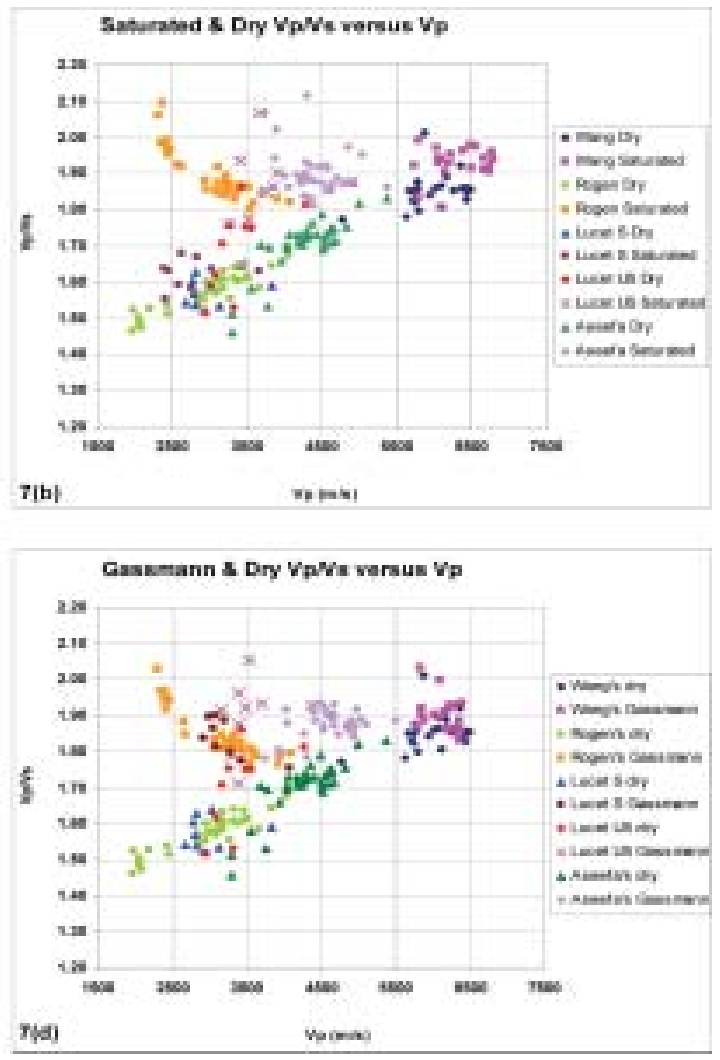

Fig.7. Plotting is done for separating the effect of fluid and air/gas in the pores and is shown as, a) Saturated and Dry Vp/Vs versus Porosity, b) Saturated and Dry Vp/Vs versus Vp. The plotting of Gassmann derived velocity values is done at c) Gassmann and Saturated Vp/Vs versus Porosity and d) Gassmann and Saturated Vp/Vs versus Vp, to show that Gassmann velocities can be used to model the saturated velocities despite the fact that the assumption of a constant shear for the rock is largely not followed by most of the data sets considered here. The $\mathrm{Vp} / \mathrm{Vs}$ ratio is 1.90 for low porosity rocks and decreases linearly up to 1.45 with increase in porosity up to $45 \%$ porosity. Plotting of Vp/Vs versus Vp is an excellent tool for differentiating formation filled with fluid from that of gas. For low porosity data this difference is not very appreciable but as the porosity increases the difference becomes more and more prominent. As in this case the difference of $\mathrm{Vp} / \mathrm{Vs}$ versus $\mathrm{Vp}$ is 0.05 for low porosity data but is as large as 0.60 for high porosity data set.

$\mathrm{V}_{\mathrm{P}}$ (fig.7b) displays a comparable variation for $\mathrm{V}_{\mathrm{p}} / \mathrm{V}_{\mathrm{S}}$ for the dry and the fluid filled formations. The $\mathrm{V}_{\mathrm{P}} / \mathrm{V}_{\mathrm{S}}$ reaches a maximum of 2.10 for high porosity data where as the same formation with gas filled pores has the value of around 1.45. This difference of 0.65 is a significant difference to spot for the formation where AVO study has to be carried out. The Gassmann $\mathrm{V}_{\mathrm{P}} / \mathrm{V}_{\mathrm{S}}$ when plotted against the porosity and the $\mathrm{V}_{\mathrm{P}}$ (fig.7c \& 7d) presented almost same (slight underestimation for low porosity samples) pictures. The low porosity data does not have any appreciable difference of ratios to spot for the porosity or substitution of fluid effects in the formation. However, when the porosity increases the difference starts building up clear and has value of around 0.50 for the porosity effects and around 0.55 for the fluid effects for the same high porosity data.

\section{Conclusions}

The Gassmann calculated velocities and modulus underestimates the saturated velocities and modulus, especially for the low porosity formation where there is no variation of shear after saturation. The effect of fluids does not seem to play an important role in these formations for calculating saturated velocities. For the high porosity formation, the Gassmann's overestimation of $V_{P}$ and $V_{S}$ is much more than what can be explained by density effect. The fluid in the rock seems to have played major role in the altering the shear strength of the rock. Though the determination of $\mathrm{V}_{-\mathrm{P}}$ and $\mathrm{V}_{\mathrm{S}}$ is inaccurate in the shear altered rocks, the theory has successfully modelled the variation in the $\mathrm{V}_{\mathrm{P}} / \mathrm{V}_{-\mathrm{S}}$ ratio for the effect of both porosity and fluid as it is known to do for clastics and also to lay checks for proposed AVO study of an area. The use of Gassmann equation for 
carbonate rocks needs to be understood better before applying them for forward models.

\section{Acknowledgement}

We are extremely grateful to Prof. G Mohan for providing all the lab facilities for the completion of this work. Permission accorded by Oil and Natural Gas Corporation Ltd. for presenting this work at the SPG convention is very much acknowledged.

Views expressed in this paper are that of the author only and may not necessarily be of ONGC.

\section{Reference}

Assefa, S., McCann, C and Sothcott, J. 2003. Velocities of compressional and shear waves in limestones: Geophysical Prospecting, 51, 1-13

Castagna, J.P., Batzle, M.L. and Eastwood, R.L. 1985. Relationships between compressional-wave and shear-wave velocities in clastic silicate rocks: Geophysics, 50, 571-581.

Castagna, J.P., Batzle, M.L. and Kan, T.K. 1993. Rock Physicsthe link between rock properties an AVO response In: Offset dependent reflectivity- Theory and practice of AVO analysis, Investigations in Geophysics; no. 8 (eds. Castagna, J. P. \& Backus, M. M.), SEG, 135171.

Eberli, G.P., Baechle, G.T., Anselmetti, F.S, and Incze M.L. 2003. Factors controlling elastic properties in carbonate sediments and rocks: The Leading Edge, July 2003, 654-660
Japsen, P., Wagner, H., Gommesen, L., \& Mavko, G. 2000. Rock Physics of chalk: Modeling the sonic velocity of the Tor Formation, Danish North Sea. In: EAGE 62 ${ }^{\text {nd }}$ Conference and Technical

Li, Y., and Downton, J., 2000. Application of amplitude versus offset in carbonate reservoirs: Re-examining the potential: SEG Expanded Abstracts, 166-169.

Lucet N., 1989. Vitesse et attenuation des ondes elastiques et ultrasoniques dans les roches sous pression de confinement: A L'UNIVERSITE DE PARIS VI

Rafavich. F., Kendall C., and Todd T.1954. The relation between the acoustic properties and the petrographic character of carbonate rocks. Geophysics 49, 1622-1636

Rogen B., 2002. North Sea Chalk- textual, petrophysical and properties: Ph. D. thesis, Environment \& Resources DTU, Technical University of Denmark.

Wang, Z.,2002. Seismic anisotropy in sedimentary r ocks, Part 2: Laboratory Data: Geophysics, 67, 1423-1422

Wang, Z.,2000a. the Gassmann equation revisited : Compaing Laboratory data with Gassmann's Prediction in Wang, Z., and Nur, A., Eds., Seismic and Acoustic Velocities in reservoir rocks, 3: Recent Development: Soc. Expl. Geophys., 8-23.

Wang, Z., and Nur, A-2000c. Velocity Relationships in Granular Rocks, Eds., Seismic and Acoustic Velocities in reservoir rocks, 3: Recent Development: Soc. Expl. Geophys., 377-383

Wilkens R., Simmons G., and Caruso L.1984. The ratio $\mathrm{V}_{\mathrm{p}} / \mathrm{V}_{\mathrm{S}}$ as a discriminant of composition for siliceous limestones. Geophysics 49, 1850-1860 